REVISTA CHILENA DE LITERATURA

Noviembre 2008, Número 73, 57 - 79

\title{
LAS RELACIONES ENTRE CIENCIA, ESTÉTICA Y POLÍTICA EN LA NUEVA ESPAÑA DE 1680
}

\author{
Luz Ángela Martínez \\ Universidad de Chile \\ luzmartine@gmail.com
}

RESUMEN / ABSTRACT

Centrado en los Arcos de Triunfo, Teatro de Virtudes Políticas de Carlos de Sigüenza y Góngora y el Neptuno Alegórico de sor Juana Inés de la Cruz, el artículo aborda las relaciones entre ciencia, estética y política en la Nueva España de 1680.

Palabras clave: Arcos de Triunfo, Carlos de Sigüenza y Góngora; ciencia, estética y políticas novo hispanas, sor Juana Inés de la Cruz; Teatro de Virtudes Políticas, Neptuno Alegórico.

This essay focuses on the relationships between science, aesthetics and politics in 1680 New Spain, as illustrated by the triumphal archs in the texts of Carlos de Sigüenza y Góngora (Teatro de Virtudes Políticas) and Juana Inés de la Cruz (Neptuno Alegórico)

KEY WORDS: Triumphal Archs, Carlos de Sigüenza y Góngora, Juana Inés de la Cruz, science, aesthetics and politics.

Proyectado sobre la historia latinoamericana, el año de 1680 marca un hito en la configuración y desarrollo tanto de nuestra estética como de nuestra identidad, pues esta fecha reúne varios acontecimientos relacionados entre sí de distinta manera con la vida colonial de Nueva España.

En el orden político, el primer acontecimiento - generador de todos los que vienen a continuación- es la llegada del esperado virrey conde de Paredes para asumir el gobierno del Virreinato. En el orden estético, el 
segundo acontecimiento lo configuran los dos Arcos de Triunfo erigidos en honor y recibimiento del nuevo gobernante, con los que las autoridades eclesiásticas y civiles buscan realzar el acontecimiento político y darle el fasto correspondiente a la celebración popular. Una de estas impresionantes "fábricas" es el polémico Teatro de Virtudes Políticas que Constituyen a un Príncipe (Sigüenza 177), con el que el criollo Carlos de Sigüenza y Góngora desconcierta e incomoda a una buena parte de la sociedad colonial -y al mismo virrey- al erigir a dioses y monarcas precortesianos como modelos de virtud política y, junto a aquello, por proclamar el concepto de Patria indisolublemente unido al territorio de Nueva España -y/o "nuevo mundo". La otra no menos significativa "fábrica", es el Neptuno alegórico, océano de colores, simulacro político (de la Cruz, sor Juana 777), en cuya "explicación" la monja de claustro sor Juana Inés de la Cruz elabora la teoría de la imagen barroca indiana. En el ámbito que atañe a la Filosofía Natural, el tercer acontecimiento que dramatiza la agitada fecha es la aparición del famoso cometa de 1680, acompañado de la ola de terror en que por esos tiempos estos astros sumergían a nobles y plebeyos, letrados e iletrados. A inicios del año siguiente y desprendido de la órbita del temido cometa, el cuarto acontecimiento significativo revela la relación entre ideología y saber en la cultura colonial. Se trata de la bullada "Controversia Cometaria" entre Sigüenza y el jesuita europeo Eusebio Kino, en la que el sabio criollo defiende la producción de conocimiento en la Colonia y denuncia la posición ideológica desde la cual el logocentrismo europeo -representado por Kino- desacredita y anula ese saber.

En este contexto, el sobrado interés que suscita cada una de estas obras $\mathrm{y}$ hechos solo es sobrepasado si abandonamos la natural inclinación al análisis individual y, por el contrario, optamos por una visión de conjunto y observamos que, en un orden más amplio, obras y hechos configuran un "sistema" o "complejo relacional" sumamente iluminador de la dinámica cultural del Virreinato.

La adopción de esta perspectiva permite advertir, por ejemplo, que la Disputa de don Carlos y su decidida oposición al logocentrismo dogmático europeo no es un hecho aislado o totalmente ajeno al acontecimiento político y a las obras estéticas que lo celebran, sino un hito cultural a partir del cual se derivan significativas directrices para analizar los otros acontecimientos de 1680. Para comenzar a establecer las relaciones que así lo indican, observemos primero que la importancia de su oposición a Kino no radica tanto en la novedad que registra y territorializa en la Colonia el enfrentamiento entre 
la Autoridad (Kino) y la Razón (Sigüenza), pues la lectura de las Historias Naturales del "nuevo" mundo muestra que desde el siglo XVI la experiencia de la realidad natural y geográfica americana cuestiona y deroga tempranamente los fundamentos de la ciencia medieval y renacentista; es decir, los de la Autoridad ${ }^{1}$. Mejor localizada en el complejo relacional en que se desarrolló, la Disputa del criollo trasciende para la historia de nuestra identidad porque necesariamente enlaza la defensa de la producción de conocimiento colonial con el concepto de Patria políticamente representado unos meses antes en su Arco de Triunfo. A su vez, la visión de conjunto indica que la "fábrica" de Sigüenza amplía y enriquece el circuito de relaciones a observar, en tanto que en ella se realiza el comentario de la ejecutada por sor Juana para la misma ocasión.

De tal manera, los vínculos que comunican hechos y obras no solo llaman nuestra atención sobre el sistema de referencias y citas entre ciencia, estética y política producido por la dinámica social de la Nueva España de 1680, sino, además, sobre la necesidad de relacionar las orientaciones ideológicas con las que en distintas obras los intelectuales criollos abordaron estos tres complejos órdenes culturales.

Sin duda, esta orientación pronto rinde sus frutos, pues si focalizamos la producción intelectual de Sigüenza entre 1680 y 1681, específicamente el asunto de la "Disputa Cometaria", la forma en que se desarrolló y los otros elementos culturales con los cuales se relaciona, surgen a la vista aspectos importantísimos de la mentalidad criolla barroca y grafican con meridiana claridad los conflictos que la asediaban. En primer lugar, tenemos que los argumentos científicos esgrimidos por Sigüenza en la Disputa rebaten las distintas opiniones que han afirmado la pobreza de la producción intelectual colonial, pues a la luz de la historia de las ideas científicas, don Carlos se presenta como un calificado representante del espíritu experimental y matemático que diferenció esencialmente la ciencia moderna del paradigma medieval europeo. En el orden de los conflictos políticos padecidos por el intelectual barroco indiano, sin duda alguna condicionantes de su contexto de producción y de sus desarrollos, encontramos que su conocimiento científico -moderno- fue invalidado por un intelectual representante del centro

La habitabilidad de la zona tórrida es un buen ejemplo; la demostración geográfica del falso fundamento de la ecumene es otro. 
hegemónico o logocentro, aun cuando el saber de este último solo tenía por fundamento la superchería y por avales el dogma y el poder. En el punto en el que hasta hoy se unen ideológicamente producción intelectual y geografía ${ }^{2}$, la Disputa deja en claro que la falaz invalidación de Kino se asienta en la supremacía territorial del saber europeo sobre cualquier otro producido en un territorio "extra europeo" (Burke).

Las consecuencias históricas que se desprenden de la Disputa, entendida como modelo de imposición política y cultural, demandan sin duda nuevos análisis que vengan a acompañar los ya realizados por destacados latinoamericanistas. No obstante la necesidad de aquello, para dilucidar el complejo de relaciones que nos ofrece el 1680 novohispano, lo que me interesa resaltar aquí es que ese territorio "extra europeo" que está siendo conceptualmente definido en la Disputa como "territorio productor de conocimiento", ya ha sido estéticamente representado y/o apropiado por la misma conciencia que así, en la condición de propio, lo expuso y comunicó a su comunidad en el corazón mismo de la fiesta popular y frente al representante del centro hegemónico. Esta afirmación se sostiene, claro está, en el acuerdo de que la representación es la manera humana de apropiarse de lo real; o lo que es lo mismo, de crear la realidad. De tal manera, "el territorio de conocimiento" de la Disputa se levanta y define sobre el ente simbólico -la Patria americana- emanado de los mecanismos creación-apropiación puestos en operación por Sigüenza en el Teatro de virtudes politicas. En este orden o concatenación de estética, política y epistemología, tenemos que la "Patria epistemológica" es susceptible de existir porque previamente se enunció la "Patria poética"; o, si requiere, porque la enunciación poética previamente dio existencia a la Patria.

Ahora bien, si ampliamos nuestra perspectiva y ponemos los hechos del 1680 novohispano en el plano de las grandes trasformaciones culturales y en la perspectiva del cambio de mentalidades acaecido en el siglo XVII, nos encontramos con que la misma disputa sobre los astros y sus órbitas -particularmente la del cometa en cuestión- fue el elemento que puso en jaque los fundamentos teológicos de la cosmovisión europea y dio lugar a lo que

2 No olvidemos que hasta la década final del s. XVI la ecumene era, a la vez, territorio teológico, simbólico y geográfico. La unión entre producción de conocimiento y geografía se extiende hasta el pensamiento moderno. Las opiniones de Hegel sobre el continente americano son un buen ejemplo. 
la Filosofía de la Ciencia registra ampliamente como la "crisis de conciencia europea" (Trabulse). Si seguimos por la misma senda y observamos las repercusiones de la discusión epistemológica en la mentalidad criolla representada por Sigüenza, no deja entonces de ser significativo que en nuestro ámbito ese mismo hecho se imbrique con la celebración barroca indiana de la que tanto hemos hablado, especialmente con sus expresiones estético-políticas, y que asistamos en ellas al despunte de una -nueva- conciencia que, aun cruzada por múltiples conflictos, monumentaliza estética y políticamente el anuncio de su autodeterminación. Evidentemente, la discusión epistemológica tiene repercusiones culturales de distinto signo en el "viejo mundo" y en el "nuevo mundo": allá, la "depresión" de la conciencia europea que ve desquebrajarse los fundamentos de su cosmovisión y que resuelve su angustia con el proyecto universal de la evangelización ${ }^{3}$; acá, el nacimiento de una conciencia autodeterminada, intelectualmente afín a la nueva concepción de la "maquina universal".

El curso de las relaciones que hemos seguido necesariamente nos lleva a fijar la atención en esos dos monumentos protagonistas de la fiesta pública barroca en los cuales, como se ha dicho, la expresión estética y la simbólica tienen la misma importancia. Si lo efímero de los arcos indianos nos privó de la dimensión plástica y escenográfica que los configuraron, para fortuna de los estudios sobre el barroco, los textos que los acompañaron salvaguardaron la expresión simbólica y, en el caso de Sigüenza, la relación de aquella con la conciencia criolla y la política.

A primera vista, el lector de estos textos se puede quedar con la impresión de marcada diferencia entre ellos. El de Sigüenza, por ejemplo, como varias de sus obras, esgrime una posición de defensa y ataque en contra de sus detractores. En este caso puntual, tal actitud se debe a la necesidad de contestar a las críticas de las que fue blanco por utilizar dioses y héroes precortesianos -los "mexicanos emperadores que en verdad subsistieron" (Sigüenza 175) - como modelos de virtud para aleccionar al virrey entrante; $\mathrm{y}$, en directa relación con esos modelos, por incluir citas de las Sagradas Escrituras en el plan general de la obra. Bien se sabe que tales críticas expresan

3 El mismo Kino es un excelente ejemplo de aquello: siendo un representante del dogmatismo teológico-científico que se derrumba, abandona Europa y la discusión intelectual para dedicar su vida a la evangelización de los indios americanos. 
en verdad el conflicto político e ideológico entre "gachupines" y "criollos"4, pues el asunto de las Sagradas Escrituras aparece también en el Arco de sor Juana -como en tantas otras obras de la época- sin que ahí haya despertado resquemores ni cuestionamientos ${ }^{5}$. En concordancia con esta otra polémica en varios sentidos antecesora de la Disputa, el Preludio II de la explicación del Arco comienza con una declaración de amor a la Patria-Nueva España y con una firme contestación a aquellos que criticaron su Arco:

"El amor que se le debe a la patria es causa de que, despreciando las fábulas, se haya buscado idea más plausible con qué hermosear esta triunfal portada.

Escollo en que peligrase el acierto pudiera juzgarse mi idea en la disposición formal del arco, que aquí describo lo extraordinario, como si apartarse de las trilladas veredas de los antiguos fuera acercarse al precipicio y al riesgo" (Sigüenza 172).

El titulo del Preludio recién citado justifica la -aparente- diferencia entre los Arcos, pues famosa es la diatriba de Sigüenza en contra "mendigar" los motivos de la representación en "fábulas mentirosas" ajenas a la leyenda y a la historia de la propia Patria. Esta posición es sostenida por don Carlos con una fuerza y convicción solo comparables a la indignación que -por similares motivos- le provoca el desprecio de los intelectuales europeos frente al trabajo intelectual de los criollos. No obstante, en este punto Sigüenza exhibe una sola posición, su crítica se suspende y toma muy otros rumbos cuando se refiere al Arco de sor Juana, cuya figura central es el mitológico Neptuno, ciertamente buen ejemplo de fábula mentirosa y ajena, es decir, de aquello que enfáticamente critica e invalida.

Antes de que caigan sobre nuestro criollo acusaciones de flagrante contradicción, y de atraer una serie de antecedentes para demostrar que esa es

4 Bien vale la pena observar que en México el enfrentamiento entre gachupines y criollos cobra ribetes teológicos tal y como lo muestra la división del culto mariano entre aquellos que sentían devoción por la Virgen de los Remedios traída por los conquistadores, popularmente conocida como "La Conquistadora o Gachupina", y aquellos otros devotos de la Virgen de Guadalupe o "Criolla". El criollo Sigüenza, por supuesto, fue exaltado devoto de la Virgen de Guadalupe.

5 Aunque en esta obra en particular no se da la misma situación de defensa y ataque, como es bien sabido, configura basalmente otros famosos textos de la monja. 
una imputación sin fundamento, es necesario señalar previamente que la referencia a sor Juana se abre en dos direcciones enriquecedoras del complejo relacional que venimos observando. En una de ellas, el criollo sorprende con unas opiniones sobre el trabajo de la monja que hoy nos parecen una adelantada y lúcida defensa de los "ingenios femeninos" y de su producción intelectual. Sin embargo, la sorpresa que nos causan las declaraciones de un sujeto del siglo XVII se desvanece y en su lugar se nos revela una sólida declaración de principios si, nuevamente, colocamos sus declaraciones en el contexto de aquel agitado año. De su compatriota intelectual, Sigüenza dice lo siguiente:

\begin{abstract}
"Prescindir quisiera el aprecio con que la miro, de la veneración que con sus obras granjean para manifestar al mundo cuánto es lo que atesora su capacidad en la enciclopedia y universalidad de sus letras para que se supiera que en un solo individuo goza México de lo que en los siglos anteriores repartieron las Gracias a cuantas doctas mujeres son el asombro venerable de las historias... Pero le hiciera agravio a la Madre Juana si imaginara el compararla aun con todas, porque ni aun todas me parecen suficientes para idearla, por ser excepción admirable de cuantas con vanidad puedan usurpar lo de Eurípides en Medea: 'Acarícianos también a nosotras las Musas y, por su sabiduría, están entre nosotras; pero entre muchas encontrarás unas cuantas, verdadera estirpe de no indoctas mujeres" (Sigüenza 177).
\end{abstract}

Más allá de la justificada admiración que el trabajo intelectual de sor Juana produjo en sus contemporáneos -europeos y americanos-, observemos que el elemento central alrededor del cual Sigüenza organiza la alabanza es México: la Patria de su Arco y el "territorio intelectual" de la Disputa, del cual sor Juana es uno de sus más excelsos e incuestionables ejemplos. Este desplazamiento del sujeto por el ente simbólico se justifica en tanto el objetivo de la alabanza es "manifestar al mundo" la capacidad enciclopédica y la universalidad de conocimientos que ahí se tiene; en tal medida, que en ese territorio intelectual y simbólico se encuentra la excepción suprema de la "verdadera estirpe de no indoctas mujeres".

Desafortunadamente, los estudios literarios nos tienen acostumbrados a leer este tipo de texto como ejemplo de la exageración propia de la retórica barroca; o, lo que es lo mismo, como intrascendentes expresiones de ocasión sin mayor contenido y objeto que el adorno lingüístico de la circunstancia que los suscita. Pero lo cierto es que el trasfondo del diálogo entre la Disputa 
y el Arco desacredita esa mal enquistada opinión. A la luz de esto último, lo que se advierte en la alabanza a sor Juana es que quien la enuncia establece una identificación entre el lugar geográfico -México-, el ente simbólico de su propio discurso - la Patria- y la sujeto ahi nacida -la monja mexicana. La dinámica de las identificaciones evidencia que, desde la perspectiva del enunciante, el ejercicio del saber realizado por la ahí nacida transfigura el primero de los anteriores elementos en el segundo; asimismo, deja claro que la ahí nacida se constituye a sí misma en el ejercicio de esa transfiguración. De tal manera, la alabanza puntual a sor Juana retrocede para dejar en primer lugar un discurso en virtud del cual el ahi nacido, el intelectual criollo, es la Patria, de la misma manera que la Patria es el ahí nacido. No está de más señalar que en esta operación resulta indiferente si sustituimos el nombre de sor Juana por el de Sigüenza, ya sea como autor o sujeto del discurso, porque el resultado es el mismo. Y lo es, porque el espíritu que mueve a Sigüenza y a la monja a su vez los define y unifica en su calidad de intelectuales barros coloniales. Sin recurrir a sus famosas cartas, de sor Juana, por ejemplo, basta con atraer el romance epistolar conocido como "Grande Duquesa de Aveyro", o el dedicado a don Pedro Velásquez de la Cadena, "Yo, menor de las ahijadas" (De la Cruz, sor Juana 47 y 60), para ejemplificar con ellos el amor a la Patria y la identificación de ésta con el conocimiento y el sujeto que lo produce.

Dijimos unos párrafos atrás que la referencia a la "Madre Juana" se abría en dos direcciones en el marco del complejo relacional de 1680. La segunda de ellas, se relaciona con las denostadas "fábulas ajenas y mentirosas" y la paradójica defensa de Neptuno como idea central a partir de la cual sor Juana organizó la representación alegórica de su Arco. De hecho, Sigüenza titula el Preludio III como sigue:

"Neptuno no es fingido dios de la gentilidad sino hijo de Misraím, nieto de Can, bisnieto de Noé y progenitor de los indios occidentales" (Sigüenza 176).

Un poco después de esa afirmación, aplaudirá la elección estética de sor Juana porque -al igual que los antiguos monarcas mexicanos- no es "Neptuno quimérico rey o fabulosa deidad sino sujeto que en realidad subsistió". Más allá de justificar tal defensa con el fácil recurso a la variedad de leyendas sobre el origen de los americanos, debemos preguntarnos por los motivos en que se asienta y las lógicas que guían la aparente contradicción del criollo.

Para encontrar la respuesta, en primerísimo lugar debemos acudir al plan y a la estructura de la obra. Ya el título del Preludio III ofrece directrices que 
no se pueden desatender, pues en él, Sigüenza niega la condición mitológicatrascendente de Neptuno y le otorga una existencia histórica, lo "historiza"; es decir, opera una "transfiguración inversa" en virtud de la cual la entidad divina deviene en un sujeto histórico cuyo árbol genealógico se testifica, sin embargo, con la Historia Sagrada y se ratifica, a su vez, etimológicamente con la historia profana. Esta operatoria que reduce una dimensión a la otra y permite el paso o el descendimiento de lo trascendente a la historia, es susceptible de realizarse porque Sigüenza pone en función el concepto "divinidad gentil", con que el humanismo y el arte renacentista pudieron incorporar los dioses de la antigüedad.

Este proceso "migratorio" que reduce o anula la dimensión sacra de los personajes mitológicos, aplicado a los "personajes" del Arco, es el que permite a Sigüenza hacer del dios Huitzilopochtli el primer modelo de virtud, en tanto, en el plano de lo heroico-histórico, el "valeroso Huitzilopochtli" deja de ser una divinidad mentirosa y/o herética ciertamente cuestionable, y se convierte en el primer "caudillo conductor de los mexicanos" en el viaje y demanda de las tierras que conforman la Nueva España del siglo XVII (Sigüenza 177). Como vemos, el asunto territorial vuelve a ser aquí un tema importante, pues asentándose el Virreinato en las tierras conseguidas por los esfuerzos del "valerosos caudillo", ciertamente queda enmarcado en la legalidad política de lo previamente conseguido por este sabio "monarca mexicano". En el orden cívico y político celebratorio colonial, no es difícil, entonces, advertir la estrategia desplegada por el Arco, ni cómo con ella se invierte la jerarquía valórica que justificó en tantos ámbitos la supremacía del español, pues, evidentemente, en este otro establecimiento de los hechos, Huitzilopochtli es el merecedor del reconocimiento y gratitud de quien en ese momento va a asumir la conducción del floreciente Virreinato: el virrey.

Sin duda, la historización de Neptuno y la afirmación de su progenitura mexicana conecta las dos "fábricas"; de tal manera que desde esta perspectiva -al parecer, también desde la de Sigüenza- la representación de ambos puede ser leída como un solo discurso. ¿En qué se justifica aquello? Anotemos que en la explicación del suyo, sor Juana hace una larguísimo recorrido por la cultura para vincular a Neptuno y Misraín y a este último personaje con la fundación de Egipto. Asimismo, en las dos explicaciones encontramos idéntico argumento en virtud del cual es viable la historirzación del sujeto mítico: aquellos a quienes la gentilidad llamó dioses fueron en verdad príncipes excelentes, inventores, sabios, que por sus virtudes se les otorgó la divinidad (De la Cruz, sor Juana 188 y 196). 
La insistencia de estos dos destacados barrocos indianos en las mismas ideas no debe caer en el expediente invalidatorio de la "rareza barroca", ni decaer en su significación simplemente por el hecho de haber sido tomadas de autores de la Antigüedad - de Plinio, según declara la monja. Un análisis centrado en la circulación de las ideas en la Colonia debe preguntarse más bien por qué algunas de ellas cobraron tan intensa vitalidad y con qué otros elementos se articularon para crear nuevos campos de sentido. Este es el caso de lo que podemos llamar desde ya la "historización mitológica" realizada por el intelectual barroco colonial. Muchas veces se ha dicho que el criollo, conflictuado por su doble ascendencia -o triple, si es que no seguimos desechando el elemento racial negro ${ }^{6}$-, intenta solucionar su angustia vital creándose un pasado mitológico precolombino. Esta afirmación es válida pero incompleta, pues debe añadirse que con esa (re)creación, el criollo propone a la cultura una novedad digna de mayores consideraciones: que las representaciones trascendentes de los pueblos no son legislaciones formalizadas, conferidas o impuestas de una vez y para siempre desde un "más allá" eterno, incuestionable e inamovible, sino creaciones poético-culturales imbricadas con las circunstancias históricas. Esta idea, doblemente afín a la génesis histórica del criollo y a la concepción moderna de este tipo de relatos, apunta a la creación del "mito histórico", formulado desde el marco de la historia y no de otro, tal como lo muestra la insistencia en la idea de que la "divinización" es un hecho cultural creado y asignado por los hombres, cuyo movimiento es el ascenso de lo histórico a lo trascendente y no el descenso de lo trascendente a la historia.

Desde una perspectiva distinta a la expresión de la "angustia vital", la "encarnación" en la historia de los modelos mitológicos y divinos o, en su otra cara, la elevación de sujetos históricos a la categoría de "Modelos Ideales", ciertamente revela en el barroco de Indias una particular concepción filosófica antiplatónica que desecha el "Mundo Arquetípico" situado en un indefinible "más allá", y, por el contrario, valida la caverna -la historia y su flujo; la cultura y su perpetua creación- como lugar propio de ese Ideal trascendente histórico que, por lo demás, sería el único verdaderamente existente, si atendemos con seriedad la idea que nuestros barrocos dicen

6 El elemento negro tiene importancia cultural en Nueva España. Sor Juana, por ejemplo, los hace sujetos de representación en sus famosos Villancicos. 
recoger de Plinio ${ }^{7}$ (De la Cruz, sor Juana 780). Este proceso historizador es el que sor Juana enuncia como un teoría de la representación en su Neptuno y recoge bajo el rótulo del "perfectísimo original": imagen bastarda "mitad cuerpo, mitad concepto" -Neptuno histórico o el virrey mitologizado- que habita en la "Casa del Mundo".

Ahora bien, el hecho de que Sigüenza recoja plenamente la historización de Neptuno ${ }^{9}$ (Sigüenza 177) realizada por sor Juana en su Arco, y que, además le otorgue a este sujeto histórico la progenitura de los indios occidentales, nos señala hacia los desplazamientos conceptuales en virtud de los cuales en el barroco de Indias una teoría de la representación y las obras que la concretan, se refuncionalizan política y simbólicamente. Neptuno, demuestra sor Juana y refrenda Sigüenza, es hijo de Misraím ${ }^{10}$, el sabio fundador de Egipto y, sobre todo, de las ciencias. Sin necesidad de que comprendamos la inextricable genealogía compuesta por los dos novohispanos, lo que importa aquí es que ese árbol genealógico demuestra efectivamente que Huitzilopochtli es la rama occidental-americana de esa alcurnia de la sabiduría. Apuntemos desde ya que la apropiación de Misraín el sabio y reinvención mitológica realizada por el criollo, tiene aquí objetivos específicos: por una parte, construye una "apoyatura illo tempore" que legaliza el alegato histórico de Sigüenza por el conocimiento en la famosa Disputa. Por otra, en el orden político, el tercer discurso que emana del cruce los dos Arcos opera otro desajuste o inversión en la jerarquía europeo-criollo, pues basta con leer las explicaciones para entender que el virrey entrante no solo le adeuda gratitud

7 Sor Juana, además, refrenda esta idea en "lo sagrado" con el impresionante Ego dixi: dii estis.

8 Esta imagen bastarda aparece con claridad en el poema 43 de las Obras Completas, dedicado a la Condesa de Galve, "A la misma Excma. Señora, hallándola superior a cualquier elogio". En este poema se refiere a las "bellezas vividoras/ que están sin envejecerse”; es decir, al concepto de belleza femenino ideal materializado estéticamente, corporizado por el arte, que no obstante ser ideal, encarna en mujeres individuales y como tales tienen una especial manera de existir y actuar en la realidad.

9 "Entre los mentidos dioses solo Neptuno tiene tan legitimada su alcurnia que es su nobiliario el Génesis y su historiador Moisés".

10 Misraim, según sor Juana, es la "nomenclación de Isis", la reina civilizadora que fundó Egipto, inventó las letras egipcias, descubrió el trigo y encarnó la sabiduría misma. Isis preside el docto catálogo de las mujeres sabias. El mismo, según Sigüenza, al que pertenece sor Juana. 
política a Huitzilopochtli y sus descendientes -los otros monarcas mexicanos modelos de virtud en el $\mathrm{Arco}^{11}-$, sino, además, la veneración rendida que se le debe a los divinizados por su saber.

En cuanto el Teatro de Virtudes se inserta en la tradición de los discursos de advertencia al príncipe, el asunto del modelo se plantea desde el inicio y su centralidad es apenas natural y necesaria. Sin embargo, en este caso la aparición modélica de los "renacidos monarcas y reyes mexicanos", específicamente de Huitzilopochtli, conlleva otro fenómeno que atañe más a la circunstancia colonial que a la tradición discursiva. Se trata de un fenómeno de retorno por el cual el católico Sigüenza parece contradecirse nuevamente, en tanto contesta la suplantación de imágenes realizada al inicio de la conquista por Cortés y tantos otros, pues si los conquistadores -religiosos o no-arrancaron las deidades de los altares precolombinos, él los repone en medio de la sociedad criolla investidos de los atuendos de los héroes históricos. Ya vimos el argumento que le permite esta restitución, de tal manera que si en la cultura hegemónica de la época era inadmisible cualquier otra divinidad distinta de la católica ${ }^{12}$, en el escenario histórico figurado por el Arco, el dios descendido a héroe no es ya una representación herética y/o demoníaca como afirman las crónicas de aquellos que contribuyeron a la destrucción de esta divinidad. El retorno del dios-héroe, su desalojo del altar y su reaparición en el escenario del Arco, implica, sin embargo, otra discusión sobre el conocimiento: Huitzilopochtli se desprende de la condición demoníaca, porque Sigüenza, demostrando la superioridad de sus conocimientos también en el campo de la lingüística y la etnografía, corrige y resemantiza esta figura con el verdadero significado de su nombre en cultura precortesiana: "Huitzilopochtli" es un nombre compuesto de:

“... huitzilin, que es el pajarito que llamamos chupa-flores, y de tlahuipochtlin que significa nigromántico o hechicero que arroja fuego, o como quieren otros de opchtli, que es mano siniestra" ${ }^{13}$ (Sigüenza 196).

Desde Acamapich hasta Cuauhtemoc.

12 Muy probablemente fuera del mismo modo en la conciencia de Sigüenza.

13 La cursiva es mía. 
Huitzilopochtli es esa delicada ave, nunca la invención equivocada e ignorante que registraron los cronistas, y menos el maligno Huichilobos de Bernal Díaz del Castillo. Si por un lado la corrección del nombre con su verdadero significado desmiente a los incultos, por otro, se suma a las múltiples operaciones teológicas por la cuales, sin faltar a su fe y sin riesgos inquisitoriales, el católico criollo puede reponer en la cultura colonial el elemento precolombino expulsado por el sujeto conquistador. Pero más importante aún para la configuración de nuestra identidad, la corrección por el conocimiento permite incorporar lo propio-negado de la conciencia criolla: el elemento indígena, y, en este caso, erigirlo como modelo político.

En lo que respecta a la querella por el saber, la incorporación del dios Huitzilopochtli a la cultura colonial va acompañada en el discurso de Sigüenza de una condición necesaria: el establecimiento de la escritura pictográfica precortesiana como documento, registro y fuente de una civilización. Esta instalación niega decididamente el discurso logocéntrico que desde Colón en adelante esencializó al indígena como una "tábula rasa" en la que el europeo sentía el deber teológico y moral de inscribir todo su saber. En este contexto de debate y réplica, esa escritura es esgrimida como contraescritura y corrección de las prestigiosas y cristianas crónicas e historias generales de las Indias. Veamos cómo Sigüenza la incorpora sin desestimar su materialidad.

“... siendo así que consta lo contrario de cuantas historias de los mexicanos se conservan hoy originales, pintadas en su papel fabricado de varas del árbol amacuahuitl, que ellos llaman texamaltl ..." (Sigüenza 196).

Desde el conocimiento de "cuantas" obras históricas indígenas originales -es decir, verdaderas - existen, Sigüenza contradice otras "cuantas" de autores europeos: a Antonio de Herrera, autor de Historia General de las Indias Occidentales; al padre José de Acosta, que escribió la Historia Natural y Moral de ellas; a Henrico Martínez y su Repertorio de los Tiempos; a Fray Gregorio García, autor de Origen de los indios; a Bernal Díaz del Castillo y la Historia de la Conquista de México; a Bartolomé de Góngora y su Octava Maravilla; a Torquemada, autor de Monarquía Indiana. Como se ve, la lista de los desmentidos no es menor ni poco significativa, pues incluye destacados nombres. Este solo antecedente demuestra que no es ninguna novedad que Sigüenza se enfrente a Kino en la Disputa científica, en cuanto el criollo está acostumbrado a denunciar que el saber impuesto por el europeo se levanta 
sobre bases erróneas y sin más propaga la ignorancia y el oscurantismo en la historia, en la lingüística, en la ciencia, etc.

El asunto del nombre encierra otras complejidades necesarias de observar. En el párrafo siguiente, Sigüenza hace otra aclaración que sin duda viene a resituar y aclarar aquello de la "mano siniestra" que otros quieren entender:

\begin{abstract}
"Advierto -dice el criollo-que la palabra hechicero entre estos indios tenía la misma acepción que entre los de Paraguay, donde significa hombre admirable, milagroso, obrador de prodigios, como dice el doctísimo Calancha en la Crónica de S. Agustín del Perú, lib. 2, cap. 2 , núm. 7, que es el propio y genuino significado de esta voz mago, que no solo comprendía en la antigüedad a los sabios, como (dejando de citar muchos otros) se infiere de Cornelio Agripa..., sino también de los superiores y reyes, según dice Cicerón..., con que por uno o por otro fue Huitzilopochtli merecedor de este nombre, y que degeneró, como sus acciones dicen" (Sigüenza 196).
\end{abstract}

Como bien sabemos, en un texto en el que se invalidan prestigiadas obras históricas no es menor que se validen otras. Evidentemente, aquello configura posiciones y bandos políticamente e ideológicamente contrarios que se enfrentan en su interpretación de los hechos y en la constitución presente y futura de la realidad. En este caso concreto, para refutar la visión funesta de Huitzilopochtli, extendida a los otros mexicanos emperadores por la misma lógica de la negatividad, Sigüenza atrae la obra de otro intelectual criollo, el peruano Antonio Calancha, interesado también en la observación de la naturaleza y en la cultura indígena. La atracción del "doctísimo" Calancha -así como la referencia a sor Juana- obviamente hace visible, alinea y consolida el bando de los intelectuales criollos más allá de las fronteras de Nueva España; asimismo, visibiliza la existencia de un circuito del conocimiento criollo entre los distintos Virreinatos ${ }^{14}$. Si lo anterior constituye un antecedente significativo en la Disputa por la producción del saber, en la compleja cuestión de la identidad criolla la cita de Calancha adiciona otro valor específico, pues el peruano exhibe un rasgo ausente en los historiadores

14 Otra prueba de la existencia de un circuito de la producción criolla es el romance epistolar con que sor Juana responde a un caballero del Perú. El tono y el contenido del romance muestra que el conocimiento de las obras criollas alcanzaba la profundidad del conflicto (De la Cruz, sor Juana 62). 
y cronistas españoles: la gratitud al indio o, al menos, el reconocimiento de que la grandeza y prodigabilidad de la Patria -no del Virreinato- le viene al criollo por esta herencia. Sigüenza, por su parte, asume la misma actitud:

"Y concluiré diciendo, con el docto Calancha, estando en semejante empeño... que "con estos párrafos les he pagado a los indios la patria que nos dieron, y en que tantos favores nos hace el Cielo y nos tributa la tierra'" (Sigüenza 183).

La cita de Calancha no se agota en lo que ya hemos señalado y presenta otro aspecto que debemos revisar porque se instala medularmente en la línea argumentativa de lo que Sigüenza quiere probar. Esto es: no solo en México, por toda América, desde el Paraguay hasta México, se extendió la descendencia de Misraim, el sabio, cuyo conocimiento superior obraba prodigios: la invención de las letras y las ciencias, el cultivo del trigo, según afirma sor Juana en el Neptuno. De tal manera, el peruano Calancha, sor Juana y él mismo son la réplica colonial de ese circuito amplio del saber en el "nuevo" mundo colonial.

Pero ¿de dónde, hay que preguntarse, viene esa idea de los hechicerossabios americanos, cuyo saber se instala en lo prodigioso y por qué nuestros criollos insisten en ella?

Una respuesta a aquello se encuentra en la lectura colonial de las crónicas e historias generales de las Indias, particularmente de la famosa Historia General y Natural de las Indias, de Gonzalo Fernández de Oviedo. Sin necesidad de citar párrafos y párrafos para mostrar cuan hostil y demonizadora es la visión de Oviedo hacia las creencias y cosmovisión indígenas, lo que me interesa resaltar es que, muy a pesar suyo, Oviedo se ve obligado a suspender su crítica condenatoria ante la "inexplicable" ciencia medicinal "e arte mágica" de los sacerdotes precolombinos. Ese saber que compendia la medicina, la adivinación, el conocimiento de los astros y la matemática, tan extendido y de tan alto prestigio en las Indias, afirma Oviedo, proviene de Oriente, de Persia, de Zoroastro (Oviedo 112-113); figura legendaria del iniciado en un saber superior que se mezcla en la bruma de los tiempos con la del egipcio Hermes Trismegisto, también con la de Isis de sor Juana.

Afirmaciones como las de Oviedo cobran sentido para la conciencia colonial básicamente por dos cosas: porque este cronista conoció la civilización indígena en las primeras décadas de la conquista y porque entroncan con las principales corrientes de pensamiento de los siglos XVI y XVII, sobre todo con las que el criollo ha hecho propias, en este caso, con el influyente 
Hermetismo del antiguo Egipto. De tal manera, si atendemos con seriedad la correspondencia que exhiben en este punto los dos Arcos, podemos advertir por ellos que la representación de Isis, Neptuno y Misraín tiene un objetivo más o menos explícito en la cultura colonial ${ }^{15}$ : entroncar la sabiduría de Huitzilopochtli, de sus descendientes y, en definitiva, de la civilización precolombina, con un prestigiado saber anterior al del europeo. De tal manera que el criollo del siglo XVII, doblemente receptor de ese conocimiento que le viene por Europa y por América, resulta ser el sujeto de conocimiento por excelencia, o, si se quiere, la encarnación natural de esa sabiduría. De hecho, la relación entre Huitzilopochtli y el Zoroastro de Oviedo es representada en el Arco:

“... Pintóse un brazo siniestro, no tanto porque precisamente manifestase el nombre de este capitán insigne (Huitzilopochtli) cuanto por sus significados recónditos y misteriosos... Dije fasto por el fuego de la antorcha con que se ilustraba la mano, siendo aquel no solo símbolo y expresivo de la divinidad, según lo de Máximo Tyrio, referido de Pietro Valeriano... 'los persas adoraban el fuego cotidiano como a un signo de la divinidad" " (Sigüenza 197).

Si bien este no es el lugar para ahondar en la gravitación que ha tenido el Hermetismo en las letras barrocas latinoamericanas hasta el siglo XX, no por ello debemos dejar de señalar que la relación entre nuestra cultura y Persia, Egipto y el Oriente en general, emparienta las poéticas de Sigüenza y sor Juana con las José Lezama Lima, Octavio Paz y Severo Sarduy. En el siglo XVII, como se sabe, la relación entre esas culturas distantes va a ser reafirmada en la conciencia colonial por el famoso Galeón de Filipinas, de tan influyentes mercancías en la configuración de la estética barroca indiana ${ }^{16}$.

La imagen de Huitzilopochtli portador de la antorcha o el fuego divino y civilizador ciertamente es la recreación barroca indiana de Zoroastro o de Hermes Trismegisto, a partir de la cual se opera la identificación entre Egipto y el mundo precolombino. Esta identificación, sin embargo, involucra otros

15 Creo innecesario atraer antecedentes suficientemente conocidos para demostrar que sor Juana conoce tan bien la obra de Oviedo como el saber hermético. Asimismo, la relación colonial entre Neptuno y el "nuevo" mundo.

16 Uno de los ejemplos de esta analogía es el traje de "la China Indiana", representante oficial hoy día de la identidad femenina mexicana. 
antecedentes directamente relacionados con la Disputa por el saber. El más significativo es aquel que productiviza la incapacidad logocéntrica del europeo para validar cualquier otro conocimiento ajeno a su dominio, pues su prejuicio ante el saber del indio y del americano criollo lo lleva a proponer la identificación entre el saber del primero con el influyente Hermetismo. Veamos cómo Sigüenza involucra en su argumentación a uno de los más prestigiados intelectuales europeos del siglo XVII, el jesuita Atanasio Kircher:

"Cuando hasta aquí parece que solo tiene por apoyo las conjeturas y, a no divertirme con ello de lo principal de mi asunto, puede ser que lo demostrara con evidencias, fundado en la compañía que tengo advertida entre los mexicanos y los egipcios, de que dan luces las historias antiquísimas originales de aquellos que poseo y que se corrobora con lo común de los trajes y sacrificios, forma del año y disposición de su calendario, modo de expresar sus conceptos por jeroglíficos y por símbolos, fábrica de sus templos, gobierno político y otras cosas de que quiso apuntar algo el padre Atanasio Kirchero en el Oedipon egipcíaco... que concluye: 'Baste entre tanto haber demostrado en este lugar la afinidad de la idolatría americana y egipcia, en lo que únicamente coincidíamos"” (Sigüenza 181) ${ }^{17}$.

“(...) con que se fortalece mi conjetura de la similitud (que bien pudiera decir identidad) que los indios, y con especialidad los mexicanos, tienen con los egipcios, descendiendo de Misraim, poblador de Egipto, por la línea de Nepthuim" (Sigüenza 183) ${ }^{18}$.

La categórica afirmación de Sigüenza; la coincidencia entre su texto y el Neptuno; el énfasis que agrega la cita de Kirchero, ciertamente establecen una reiteración significativa que no se puede pasar por alto o inscribirse en el expediente de "lo exótico", donde por cierto han caído muchos elementos representativos de la cultura barroca indiana. Y no puede pasarse por alto porque el recurso a lo egipcio o, más bien, al conocimiento que proviene de esa cultura, se relaciona directamente con el sistema epistemológico de los siglos XVI y XVII y con la Revolución Científica de donde surge la ciencia

17 Las cursivas son mías.

18 Las cursivas son mías. En el Neptuno, sor Juana afirma la misma relación entre Misraim y Nepthuim. 
moderna: el conocimiento místico y hermético de la maquina universa. Veamos qué dice al respecto el historiador de la ciencia Allen G. Debus:

\begin{abstract}
"Estos dos siglos (el XVI y el XVII) ofrecen un laberinto de intereses casi desconcertante y rara vez encontraremos en ellos un individuo cuya metodología científica pudiese parecer del todo aceptable a un científico moderno. Para algunos de sus sabios, cuya obra contribuyó a nuestra era científica moderna, la magia, la alquimia y la astrología fueron no menos estimulantes que el nuevo interés por la abstracción matemática, la observación y la experimentación. En nuestros días pensamos que es fácil -y necesario- separar a la "ciencia" de la afición por el ocultismo, pero en esa época muchos no estaban en la posibilidad de hacerlo. Y no podemos atribuir esa concepción mística del mundo a unas cuantas figuras secundarias actualmente olvidadas, salvo por los anticuarios. Los escritos de Isaac Newton y Johannnes Kepler (1571-1630) revelan un genuino interés por la transmutación de los metales y las armonías universales, tanto como las obras de Paracelso (1493-1541), Robert Fludd (1574-1637) o John Dee (1527-1606), (Debus 16-17).
\end{abstract}

A la luz de este antecedente y en relación con la Disputa por el conocimiento, resulta iluso pensar que la representación del "egipciaco" Huitzilopochtli o de la Isis de sor Juana, responden a una "extravagancia barroca", o que solamente son expresiones de la angustia vital del criollo en su afán de crearse un pasado mitológico: Sigüenza y sor Juana son destacados intelectuales del siglo XVII, igual que Kepler, imbuidos en los problemas epistemológicos de su época, lo que los distingue de este último, es que, además, son poetas. De tal manera, en el orden de los problemas que enfrenta la conciencia colonial, la identificación conocimiento egipcio-civilización indígena se revela más bien como un "dispositivo" poético que opera en, al menos, tres ordenes: como argumento en la Disputa intelectual; como legalización mediante la cual el criollo-católico puede reponer en la cultura colonial la divinidad expulsada por la conquista, y como agente que le permite reincorporar lo ajeno-propio y/o lo negado-propio que es para él el elemento cultural indígena.

Añadamos otra función política a la recreación mitológica de Sigüenza. Teniendo a Colón como inventor de la leyenda, hasta hoy se repite que la llegada del europeo al "nuevo" mundo confirmó en la historia una profecía precolombina: la llegada o retorno de unos hombres-dioses largamente esperados por el sujeto indígena. Aunque basta con leer varios párrafos del Diario de Colón para darse cuenta de que la identificación del europeo con 
el personaje de la profecía es simple y llanamente una falsedad, la violenta imposición del conquistador ha quedado justificada o encubierta por el mismo relato de la cosmovisión indígena. Pues bien, esta invención a la que los conquistadores muy convenientemente dieron categoría de verdad, es intervenida en el Arco. Sigüenza no cambia aquí el relato, lo que cambia es el sujeto, pues en la interpretación del criollo es a Neptuno -a su propio progenitor- a quien en verdad los indios esperaron, no a los europeos. Evidentemente, la reinterpretación de Sigüenza tiene la misma intención política del europeo, solo que en un sentido inverso y contrario a aquel, pues sin aludirlo directamente, denuncia el fraude en su interpretación y destruye con ello la aureola trascendente con la que el europeo se autoinvistió:

"Pasábaseme una singularidad curiosa, y es que eran estos indios gente que esperaba, gentem expectantem, y que esperasen es cierto, pues tuvieron profecía que había de venir a gobernarlos el que propiamente era su rey, conque los que arbitraban en el Imperio eran solo sus súbditos, esperando con la propiedad del dominio a su legitimo dueño...

Rey, en propiedad, no podía ser otro que Neptuno... y teniendo este particular dominio en las aguas mediad, que son las lagunas bien pudiera (si acaso pudiera) haber sido su asiento México, fundado en ellas... y teniendo los primeros fundadores de México a Neptuno por guía, pudieron fácilmente salir de las incomodidades de una laguna a las seguridades de una fuerte ciudad" (Sigüenza 181)".

Como vemos, Sigüenza propone claramente que lo esperado por los indios es el retorno de su propio origen, no a ningún otro que viniera a refundar su civilización; de tal manera que en propiedad "Rey" solo puede ser Neptuno o sus descendientes, quienes, en su calidad de legítimos substitutos, ostentan el dominio con la misma propiedad. Evidentemente, esta interpretación de la profecía ilegitimiza el gobierno del rey español sobre estas tierras y lo convierte, a él y sus representantes, en usurpadores.

Ahora, el incuestionable conocimiento que tenía la monja de la obra de Kirchero y el hecho de que estos dos arcos se exhibieron el mismo día, apenas a unas cuadras de distancia, inevitablemente hacen que se nos formule una pregunta ¿la monja criolliza al virrey entrante al hacerlo descendiente de Neptuno como se decía de los mexicanos? Si a partir del discurso de Sigüenza ese interrogante queda gravitando sin respuesta sobre el de sor Juana, lo que sí se esclarece con la identificación mexicanos-egipcios, es el ascendiente 
que tuvo el Hermetismo en los intelectuales de Nueva España y cómo esta corriente de pensamiento constituye un argumento fuerte en el campo de los conflictos políticos entre grachupines y criollos.

Considerado todo lo anterior, entonces ¿cómo es el "Modelo" de Sigüenza y cómo se configura? Después de negar la validez de utilizar fábulas mentirosas como modelos de los arcos de triunfo destinados a la alabanza de los gobernantes, Sigüenza dice que los reyes no son vicarios de Dios, sino "una viviente imagen suya, o un Dios terreno" y reafirma esta idea preguntándose con Enrique Farnes (de Simulacrun Reip) “ ¿No es acaso el príncipe o una imagen de Dios o algo así como un Dios terreno?" (Sigüenza 173).

Sin duda sorprenden las afirmaciones del criollo y sin embargo cobran un sentido especial si se las pone en relación con los príncipes que pueblan su Arco y no con el virrey agasajado, pues el primero de ellos es efectivamente un dios ${ }^{19}$ y los otros monarcas históricos eran positivamente considerados por su pueblo como encarnaciones de dios, hombres divinizados o divinos: Acamapich, Cuauhtémoc ${ }^{20}$, por ejemplo. Esta idea no es en nada ajena a la consideración en que los egipcios tenían a sus faraones, prácticamente, sabemos, es la misma. Pero lo significativo aquí no es precisamente aquello, sino que el "dispositivo egipcio" recreado por el criollo propone poéticamente otra fundación teológica del saber o, por lo menos, paralela a la del único dios católico: la del indígena y su otro vínculo con lo divino.

Ahora bien, la poética de Sigüenza concuerda con la de sor Juana en lo referente al poder espectacular y seductor de la imagen en el orden de lo simbólico y lo político; si bien esta convicción cruza todo el texto, queda

19 Bien se sabe que Sigüenza fue un conocedor eximio de la cultura precortesiana y de sus códices. Él mismo lo afirma cada vez que tiene oportunidad, por lo tanto, la "infiltración" del dios en el marco histórico no obedece a una casualidad o equivocación.

20 "Animóse esta hermosísima máquina de colores, por las razones que dejo escritas en el preludio II, con el ardiente espíritu de los mexicanos emperadores desde Acamapich hasta Cuauhtémoc, a quienes no tanto por llenar el número de los tableros cuanto por dignamente merecedor del elogio acompañó a Huitzilopochtli. Bisoñería fuera combinar estos doce emperadores con los doce patriarcas o con los signos celestes (empeño de más elegante pluma que la mía) cuando en la aritmética de Pitágoras, filosofía de Platón, teología de Orfeo y advertencia de Pedro Bugno... sobraban no vulgares primores para hermosear este número" (Sigüenza 187). 
especialmente clara en una cita de san Basilio de Seleucia muy afín en este punto al espíritu del barroco:

"Débole a san Basilio de Seleucia, orat 2, toda esta idea. 'Los que miran aquellas imágenes de reyes que despiden fulgor por el esplendor de sus colores, que hacen resplandecer la púrpura de flor marina, cuya diadema fulgura con los centelleos de la pedrería circundando las sienes, ésos, ciertamente, quedan atónitos con tal espectáculo, y al instante, en el arrebato de su admiración, se representan la hermosura del modelo" (Sigüenza 187).

La suntuosidad de la imagen del monarca y la grandeza suave de la pintura tienen en Sigüenza un enlace directo con la escritura precortesiana, esgrimida previamente como verdadera fuente para el conocimiento de la civilización de los antiguos monarcas mexicanos. Sin embargo, tal como en sor Juana, la relación de su pensamiento con la pintura va a ser compleja, en tanto la representación a la que apunta todo su discurso es la pintura-letra de los códices, entidad cultural esta que, si bien es central y tiene supremacía sobre los textos escritos por españoles, no es sin embargo la fuente "pura" o "directa" de donde se toma la imagen que va a animar el escenario del Arco, pues el traspaso es intervenido por la explicación suave del concepto de la conciencia autorial de la "fábrica" y del texto que la explica.

“... de las que fueron más plausibles en el discurso de su vida en el nombre de cada emperador o del modo que lo significaban los mexicanos por sus pinturas, se dedujo la empresa o jeroglífico en que más atendía a la explicación suave de mi concepto que a las leyes rigurosas de su estructura, que no ignoro..."(Sigüenza 188).

En este sentido, la intervención conceptual patentiza un hecho fundamental: si bien la representación criolla de Nueva España de 1680 no es la del español o la del europeo a secas, tampoco es la del indio. Lo que tenemos en la conciencia autoral del Arco es a un intelectual criollo en el acto de crear conceptual y estéticamente "nuestra ( $\mathrm{su}$ ) nación criolla"; consecuentemente, el texto que enuncia la Patria, no son los códices, tampoco las crónicas ni las historias del español, sino la representación del Arco y el texto explicación que lo acompaña. De tal modo, el "modelo doméstico" de virtud política no es una "imagen de Dios" -indígena o cristiano-: es, en verdad, una imagen poética criolla, es decir, una representación a la que se quiere dotar de todo el poder político y simbólico al que aspira la conciencia que la crea. 
No sin buenas razones, Sigüenza ha sido duramente criticado por sus opiniones sobre el indígena, pero si queremos observar el fenómeno de la formación de nuestra identidad, debemos aclararnos a nosotros mismos y entender que el criollo, como "el tercero en discordia" entre el indígena y el español, no está buscando una identificación con ninguno de esos dos polos y más bien los considera como aquellos escollos que debe superar $-\mathrm{y}$ dominar-para establecer, sobre el imperio azteca y el virreinato, su "propia nación criolla". De hecho, en el movimiento declarado de su alabanza a la Patria podemos dilucidar esa perspectiva, pues va del origen (el imperio azteca) a la actualidad (Virreinato), y de ahí a la proyección futura (Patria criolla). Observémoslo:

"De esta manera salí (como pude) del empeño en que me puso mi patria en ocasión tan grande, observando lo que de Platón. Lib. de Amore dice Casan... "La perfecta alabanza es aquella que describe los orígenes de una cosa que narra la forma presente y que muestra los siguientes acontecimientos". Pues en la descripción de este arco se halla el principio del mexicano gobierno y lo demás que me prometo muy cierto" (Sigüenza 231).

Lo anterior va acompañado de una fuerte declaración acerca del "crimen enorme" de disfrazar la verdad. Si visualizamos las anteriores declaraciones $\mathrm{y}$, en general, todo el discurso del Arco en los términos estratégicos en que debe moverse constantemente el criollo, tenemos que la valorización del origen político de México y "verdad" del mexicano gobierno, lo que buscan es deslegitimizar los fueros políticos del enemigo más fuerte, del español. Ahora, no por eso debemos negar a Sigüenza la visión de un México que se valida en su origen propio, tampoco dejar de advertir que ese México no es Nueva España ni tiene su origen en el imperio español.

\section{BIBLIOGRAFÍA}

Allen G. Debus. El hombre y la naturaleza del Renacimiento. Trad. Sergio Lugo Rendón. México: Fondo de Cultura Económica, 1985.

Burke, Peter. El Renacimiento Europeo. Traducción de Magdalena Chocano Mena. Barcelona: Crítica, 2000.

Colón, Cristóbal. Los cuatro viajes; Testamento. Edición de Consuelo Varela. Madrid: Alianza, 1986.

De la Cruz, sor Juana. Obras Completas. Prólogo de Francisco Monterde. México: Editorial Porrúa, 2004. 
Oviedo, Gonzalo Fernández de. Historia General y Natural de las Indias. Edición y estudio preliminar de Juan Pérez de Tudela Bueso. Madrid: Biblioteca de autores españoles, 1959.

Sigüenza y Góngora, Carlos de. Seis Obras. Prólogo de Irving A. Leonard; edición, notas y cronología de William G. Bryant. Caracas: Ayacucho, 1984.

Trabulse Elías. Ciencia y religión en el siglo XVII. México; El Colegio de México. 1974. 